University of Nebraska - Lincoln

DigitalCommons@University of Nebraska - Lincoln

Publications from USDA-ARS / UNL Faculty

U.S. Department of Agriculture: Agricultural

Research Service, Lincoln, Nebraska

2014

\title{
The biophysical link between climate, water, and vegetation in bioenergy agro-ecosystems
}

\author{
Justin E. Bagley \\ Energy Biosciences Institute (EBI), University of Illinois at Urbana-Champaign \\ Sarah C. Davis \\ Voinovich School for Leadership and Public Affairs and Department of Environmental and Plant Biology, \\ Ohio University
}

Matei Georgesu

School of Geographical Sciences and Urban Planning, Arizona State University

Mir Zaman Hussain

Energy Biosciences Institute (EBI), University of Illinois at Urbana-Champaign

Jesse Miller

Energy Biosciences Institute (EBI), University of Illinois at Urbana-Champaign; Department of Plant

Biology, University of Illinois at Urbana-Champaign

See next page for additional authors

Follow this and additional works at: https://digitalcommons.unl.edu/usdaarsfacpub

Part of the Bioresource and Agricultural Engineering Commons

Bagley, Justin E.; Davis, Sarah C.; Georgesu, Matei; Hussain, Mir Zaman; Miller, Jesse; Nesbitt, Stephen W.; VanLoocke, Andy; and Bernacchi, Carl J., "The biophysical link between climate, water, and vegetation in bioenergy agro-ecosystems" (2014). Publications from USDA-ARS / UNL Faculty. 1495.

https://digitalcommons.unl.edu/usdaarsfacpub/1495

This Article is brought to you for free and open access by the U.S. Department of Agriculture: Agricultural Research Service, Lincoln, Nebraska at DigitalCommons@University of Nebraska - Lincoln. It has been accepted for inclusion in Publications from USDA-ARS / UNL Faculty by an authorized administrator of DigitalCommons@University of Nebraska - Lincoln. 


\section{Authors}

Justin E. Bagley, Sarah C. Davis, Matei Georgesu, Mir Zaman Hussain, Jesse Miller, Stephen W. Nesbitt, Andy VanLoocke, and Carl J. Bernacchi 


\title{
Review
}

\section{The biophysical link between climate, water, and vegetation in bioenergy agro-ecosystems}

\author{
Justin E. Bagley ${ }^{a}$, Sarah C. Davis ${ }^{b}$, Matei Georgescu c, \\ Mir Zaman Hussain ${ }^{a}$, Jesse Miller ${ }^{a, d}$, Stephen W. Nesbitt ${ }^{e}$, \\ Andy VanLoocke ${ }^{a, d, f}$, Carl J. Bernacchi $a, d, f$,* \\ ${ }^{a}$ Energy Biosciences Institute (EBI), University of Illinois at Urbana-Champaign, Urbana, IL 61801, USA \\ ${ }^{\mathrm{b}}$ Voinovich School for Leadership and Public Affairs and Department of Environmental and Plant Biology, \\ Ohio University, Athens, $\mathrm{OH} 45701$, USA \\ ' School of Geographical Sciences and Urban Planning, Arizona State University, Tempe, AZ 85287, USA \\ d Department of Plant Biology, University of Illinois at Urbana-Champaign, Urbana, IL 61801, USA \\ e Department of Atmospheric Sciences, University of Illinois at Urbana-Champaign, Urbana, IL 61801, USA \\ ${ }^{\mathrm{f}}$ USDA-ARS, Global Change and Photosynthesis Research Unit, Urbana, IL 61801, USA
}

\section{A R T I C L E I N F O}

Article history:

Received 27 February 2014

Received in revised form

12 September 2014

Accepted 8 October 2014

Available online 28 October 2014

Keywords:

Bioenergy production

Biophysical climate feedbacks

Ecosystem-atmosphere in-

teractions

Land use change

Land-atmosphere interactions

\begin{abstract}
A B S T R A C T
Land use change for bioenergy feedstocks is likely to intensify as energy demand rises simultaneously with increased pressure to minimize greenhouse gas emissions. Initial assessments of the impact of adopting bioenergy crops as a significant energy source have largely focused on the potential for bioenergy agroecosystems to provide global-scale climate regulating ecosystem services via biogeochemical processes. Such as those processes associated with carbon uptake, conversion, and storage that have the potential to reduce global greenhouse gas emissions (GHG). However, the expansion of bioenergy crops can also lead to direct biophysical impacts on climate through water regulating services. Perturbations of processes influencing terrestrial energy fluxes can result in impacts on climate and water across a spectrum of spatial and temporal scales. Here, we review the current state of knowledge about biophysical feedbacks between vegetation, water, and climate that would be affected by bioenergy-related land use change. The physical mechanisms involved in biophysical feedbacks are detailed, and interactions at leaf, field, regional, and global spatial scales are described. Locally, impacts on climate of biophysical changes associated with land use change for bioenergy crops can meet or exceed the biogeochemical changes in climate associated with rising GHG's, but these impacts have received far less attention. Realization of the importance of ecosystems in providing services that extend beyond biogeochemical GHG regulation and harvestable yields has led to significant debate regarding the viability of various feedstocks in many locations. The lack of data, and in some cases gaps in knowledge associated with biophysical and biochemical influences on land-atmosphere interactions, can lead to premature policy decisions.
\end{abstract}

Published by Elsevier Ltd.

\footnotetext{
* Corresponding author. USDA-ARS, 193 E.R. Madigan Laboratory, Urbana, IL 61801, USA. Tel.: +1 2173338048

E-mail address: bernacch@illinois.edu (C.J. Bernacchi).
} http://dx.doi.org/10.1016/j.biombioe.2014.10.007 0961-9534/Published by Elsevier Ltd. 


\section{Introduction}

Between 30 and $40 \%$ of total global ice-free land is devoted to pasture or cropland [1]. Much of the remaining land is considered unsuitable, inaccessible, or inappropriate for agricultural development. The agricultural development that has occurred in recent years been focused in the tropics and has led to regional deforestation with extreme ecological and climatological consequences. The spatial and ecological limits of arable land combined with the effects of growing global energy and dietary demands in a changing climate necessitate comprehensive assessment of how to optimize the services that agro-ecosystems provide. Recently, the fraction of arable land being devoted to bioenergy production has increased, largely due to the increased fraction of harvested maize (Zea mays) being apportioned to ethanol production in the United States and increased sugarcane (Saccharum officinarum) production in Brazil (Fig. 1). The change in land use associated with increased bioenergy production will lead to biogeochemical and biophysical impacts on climate and coupled

\section{$\%$ of global biofuel production by country}

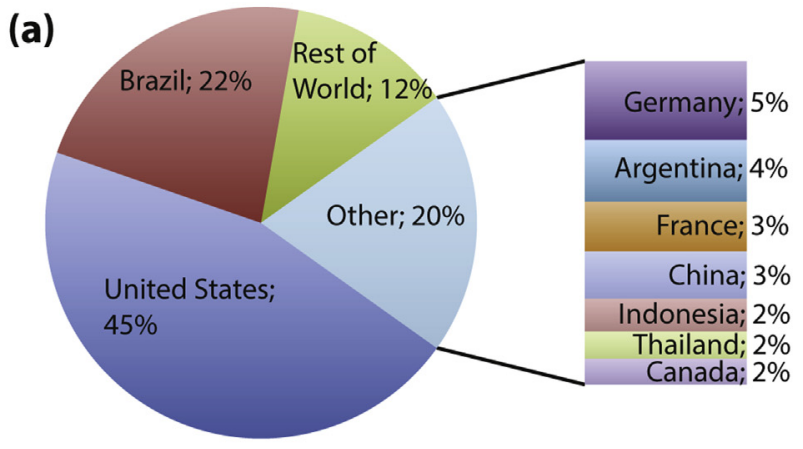

(b)

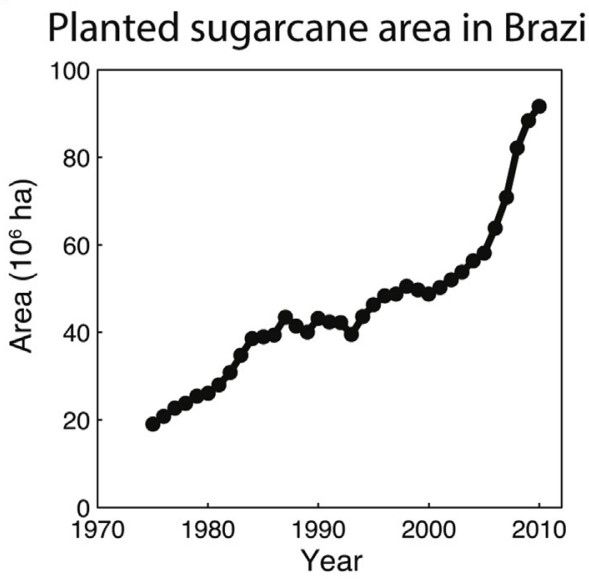

(d) Fraction of land used for sugarcane

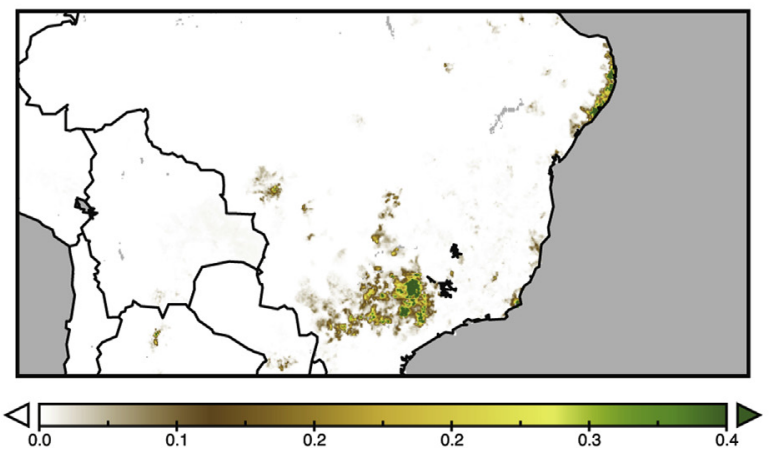

(c)

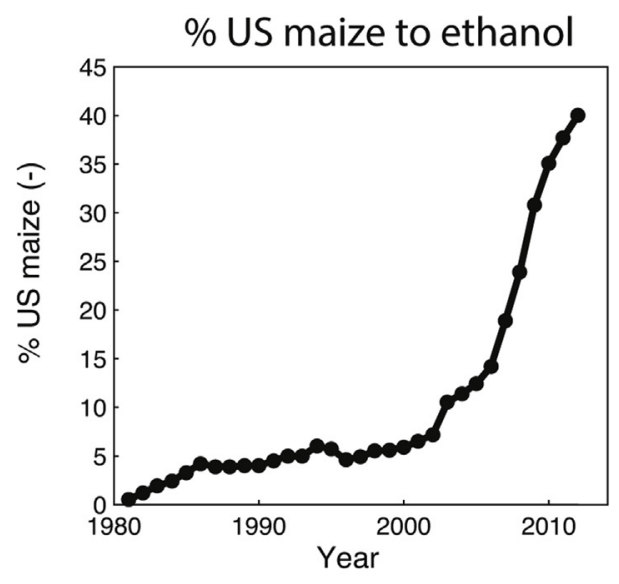

(e) Fraction of land used for maize

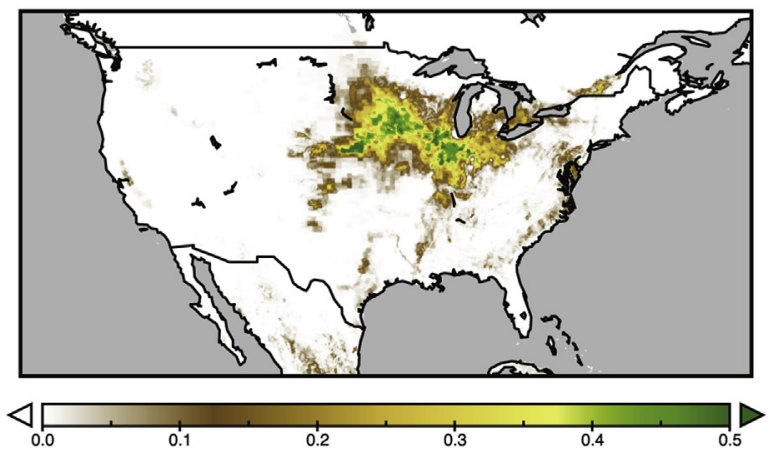

Fig. 1 - (a) 2012 global distribution of biofuel production (Source: BP statistical review of world energy [105]). (b) Total Brazilian Sugarcane Production (Source: Brazil Ministry of Agriculture [106]). (c) Percentage of US maize production utilized for ethanol (Source: USDA Statistics [107]). Map of fraction of land used for sugarcane in Brazil (d), and maize in the US (e) (Source: Monfreda et al. [108]). 
hydrological cycles [2,112]. The biogeochemical greenhouse gas impacts of expanded bioenergy agroecosystems have been extensively studied using gas exchange measurements, a variety of computational crop models, life-cycle analyses, and other analysis techniques (e.g. Refs. $[3,4,17,28])$. There are important uncertainties of the biogeochemical greenhouse gas impacts of bioenergy agroecosystems that remain due to limitations in the analysis techniques. However, the direct biophysical water and climate impacts of bioenergy expansion and the biophysical interactions with biogeochemical impacts have received far less attention, and large uncertainties on the magnitude of biophysical impacts remain.

The regulation of climate and water are important ecosystem services that can be valued across a spectrum of spatial scales. At global scales biogeochemical processes associated with changing greenhouse gasses (GHGs) are expected to dominate future changes in climate. This is one of the motivating factors for the development of bioenergy, as replacing fossil fuels with biofuel from well-designed bioenergy agro-ecosystems could reduce GHG emissions, although the potential for emissions from direct and indirect land use change remain an issue (e.g. Refs. [3,4,10]). At smaller spatial scales direct biophysical regulation of climate and water can drive the feedbacks between vegetation and local climate (e.g. Refs. $[5,7,12,63])$. Land use management or land cover changes caused by bioenergy development lead to perturbations in fluxes of moisture and energy, which influence local and regional hyrdoclimate. Just as changes in the climate system are expected to influence vegetation, changes in the distribution and composition of terrestrial vegetation are expected to modify hydrology and climate at a range of spatial scales to differing degrees [6]. For example, climate influences the extent of evapotranspiration by vegetation occurring at the surface of the earth, which subsequently alters the energy stored in atmospheric water vapor as latent heat. Water vapor is transported via atmospheric circulation and later released as latent heat when condensation occurs. This energy heats the local atmosphere, and can lead to the formation of clouds and precipitation, all of which constitute feedbacks on the climate system [7].

Bioenergy cropping systems are likely to diversify as the biofuel industry matures, ideally leading to the introduction of regionally appropriate species to the agricultural landscape [8]. The criteria for the appropriateness of a species for a region has been defined based on invasion risks, water use, climate and edaphic suitability, and a range of other metrics. Together, these criteria can promote enhanced sustainability of a given bioenergy feedstock in a certain area [9,10]. Introducing bioenergy crops that differ from existing vegetation at a given location is likely to alter local and regional hydroclimate [5,11-14,112]. The magnitude of crop-specific impacts on modulation of moisture and energy fluxes, however, remains uncertain and it is therefore difficult to assess the appropriateness of different cropping systems in the context of water cycling and biophysical climate regulation.

The water use of a given species is not necessarily transferrable from one field to the next, and the integrated response of water cycling between a regional landscape and the atmosphere does not scale directly from individual site measurements [15]. Similarly, altering the vegetative composition of a region perturbs the biophysical partitioning of energy at the earth's surface in a fashion that is closely coupled to water use. However, observations of the impact of bioenergy adoption on the surface energy budget (SEB) are sparse or nonexistent, particularly for advanced bioenergy crops. Nevertheless, quantifying the fluxes of water and energy between terrestrial ecosystems and the atmosphere are of great concern for projecting ecosystem health in response to climate change. The carbon sink strengths of recognized bioenergy crops that are being researched have been described in the scientific literature (e.g. Refs. [3,16,17]), but the water and energy balances of these agro-ecosystems have received less attention $[2,5,11,14,18]$.

Uncertainties regarding food vs. fuel and indirect land use change are leading to increased efforts to utilize abandoned, idle, and marginal lands for potential bioenergy production [19-21]. In many cases these lands have been abandoned for agriculture in the past because nutrient and water limitations associated with soil quality, climate, or both have led to agricultural production becoming uneconomical in the region. However, the extent of marginal and abandoned lands are subjected to the vagaries of global markets and politics, where rises in grain prices, changes in policy incentives, and new laws may lead to marginal and abandoned land becoming economically viable. For example, it has been recently suggested that an observed westward expansion of Midwestern US maize into marginal grasslands of the Dakotas, Minnesota, Nebraska, and Iowa could be directly tied to the rising market value of the crop [22]. The net effect of land use change on the SEB and hydroclimate may not be self-evident. Part of the uncertainty associated with these shifts in land use is due to climatic and hydrological feedbacks occurring across a potential spectrum of spatial scales ranging from the leaf to the planetary scale. At each of these scales key questions not currently understood require examination to assess the full biophysical impacts of bioenergy expansion.

Here we review the link between vegetation and climate in a bioenergy context, focusing on the following fundamental questions:

(1) How does climate dictate the potential suitability of a region for bioenergy development, and what is the potential for bioenergy agro-ecosystems to influence water cycling and climate at a variety of spatial scales?

(2) What are the open scientific questions that must be addressed at each scale to assess the biophysical climate impacts of water and energy regulating services in a bioenergy agro-ecosystem?

(3) What observational and computational tools are needed to reduce uncertainty in assessments of bioenergy feedbacks to climate?

To address these questions Section 2 describes how climatic limitations constrain the spatial extent of bioenergy agro-ecosystems, and where opportunities exist for bioenergy expansion. Section 3 reviews how the surface energy budget influences biophysical feedbacks of vegetation on climate, and introduces some key uncertainties in assessing these feedbacks. Section 4 details processes that influence biophysical water and energy regulation at the leaf, plant-field, 


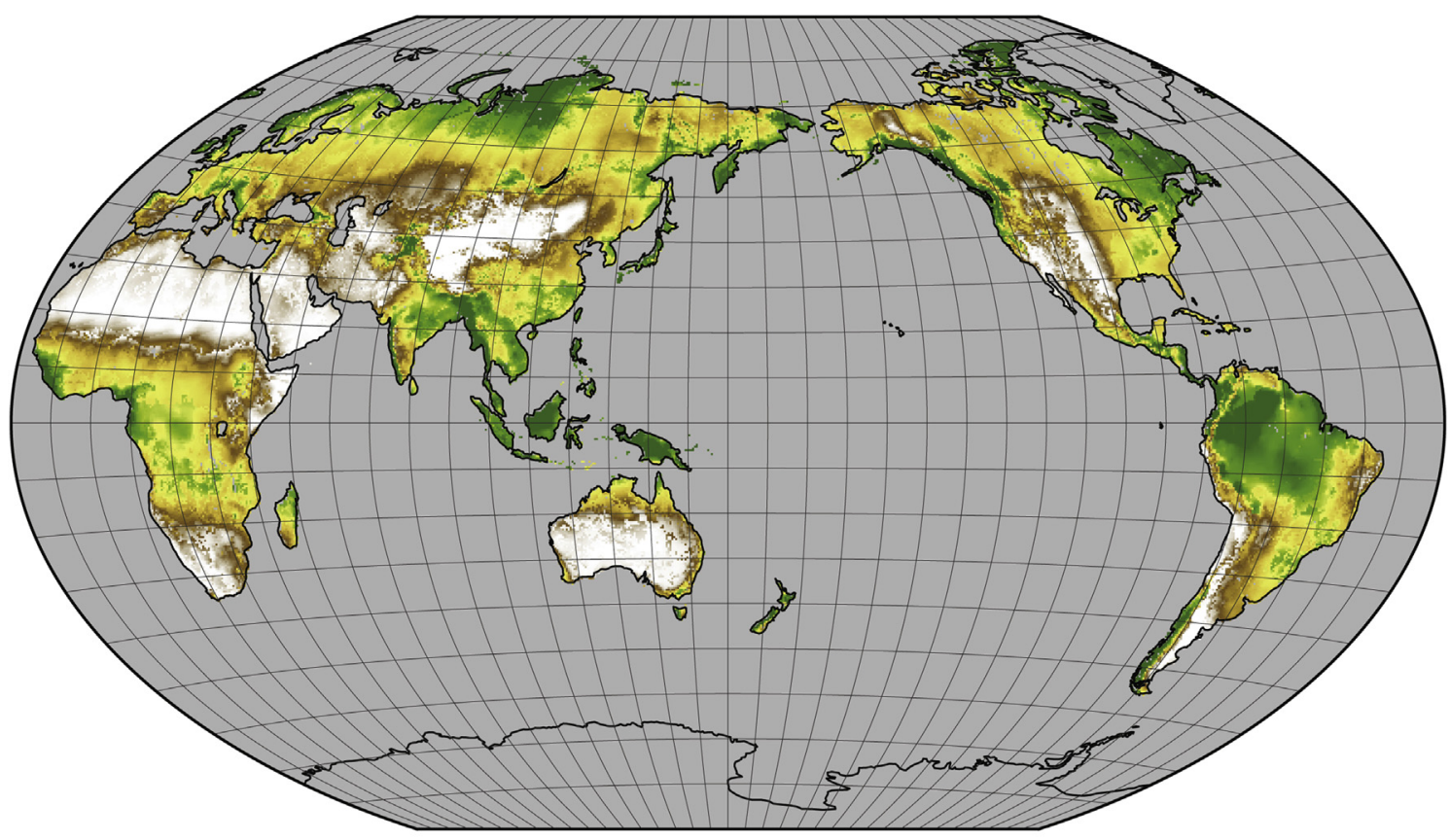

Evapotranpiration / Precipitation (-)

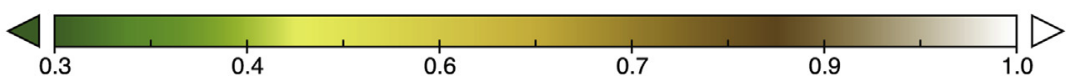

Fig. 2 - Annual ratio of evapotranspiration to precipitation modeled using a simple LSM described in Ref. [109], and potential vegetation. As the ratio becomes closer to one, potential bioenergy crops are likely to become more water-limited, and need to be adapted to thrive in arid conditions.

regional, and global scales, and presents key questions that need to be addressed at each scale to reduce uncertainty in vegetation-climate feedbacks. Specific tools needed to assess open questions across scales in the vegetation-water-climate link are presented in Section 5. Finally, Section 6 gives an outlook for improved assessments of vegetation-climate interactions.

\section{Climatic limitations and opportunities for expansion of agro-ecosystems}

The area available for expansion of bioenergy agroecosystems is limited. While the specific changes in land cover associated with agricultural expansion vary regionally, the majority of bioenergy croplands that have been developed to date have been grown in Brazil and the United States as these two countries account for approximately $68 \%$ of global biofuel production, primarily through maize (US) and sugarcane (Brazil) harvest (Fig. 1). The regional viability and productivity of agro-ecosystems, and vegetation in general, are fundamentally determined by complex soil and climatological limitations imposed by varying temperature, water, and radiation [23]. For example, patterns of water limitation can be inferred by comparing the ratio of evapotranspiration to precipitation (Fig. 2). As the annual ratio gets closer to one, productivity becomes more water-limited and the types of bioenergy crops that can be grown become restricted to those with adaptations to arid conditions.
Currently, in the United States climatological factors including precipitation and temperature (Fig. 3a,b) combine to regionally constrain viable bioenergy crops, and selecting an optimal feedstock requires balancing multiple factors [8,24]. In the Midwest US (red outline in Fig. 3b), perennial grasses such as miscanthus (Miscanthus $\times$ giganteus) and switchgrass (Panicum vergatum) are well suited to the region. These species take advantage of carbon concentrating C4 photosynthesis to generate large yields with efficient water use, minimal fertilization requirements, and permanent rooting stocks that contribute to soil organic matter. Estimates suggest that miscanthus could provide $260 \%$ more ethanol per hectare than corn grain in the region with lower environmental costs [25].

Drought tolerant and water-efficient crops such as sorghum (Sorghum bicolor) and switchgrass would be beneficial in the relatively arid Great Plains, loosely defined as the region containing Kansas, Oklahoma, portions of Texas and the Western Midwest States (Fig. 3b) [26]. In the Eastern United States, fast growing woody plants such as poplar and willow are potentially productive bioenergy crops, while along the Gulf Coast (white outline in Fig. 3b) sugarcane variants selected for high fiber content (i.e. energy cane) and tropical grasses are seen as viable crops capable of large energy yields (Fig. 3c). Although the Southwestern US may appear to be an unlikely candidate for development of bioenergy agroecosystems due to extreme water limitations, adapted regional crops are being explored for biofuel production. One adaption to water limitations that plants utilize is the 
(a)
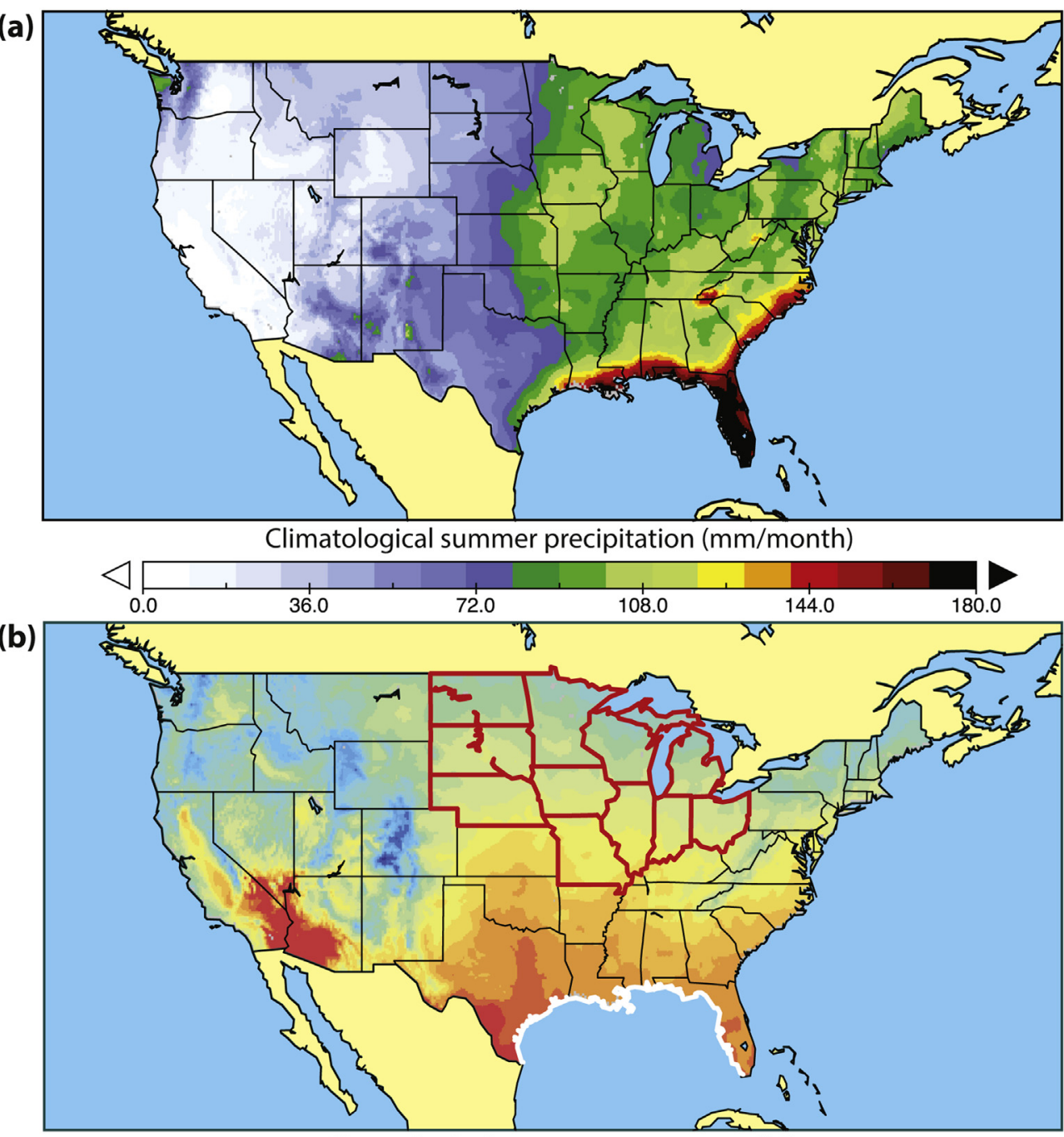

Climatological summer temperature $\left({ }^{\circ} \mathrm{C}\right)$

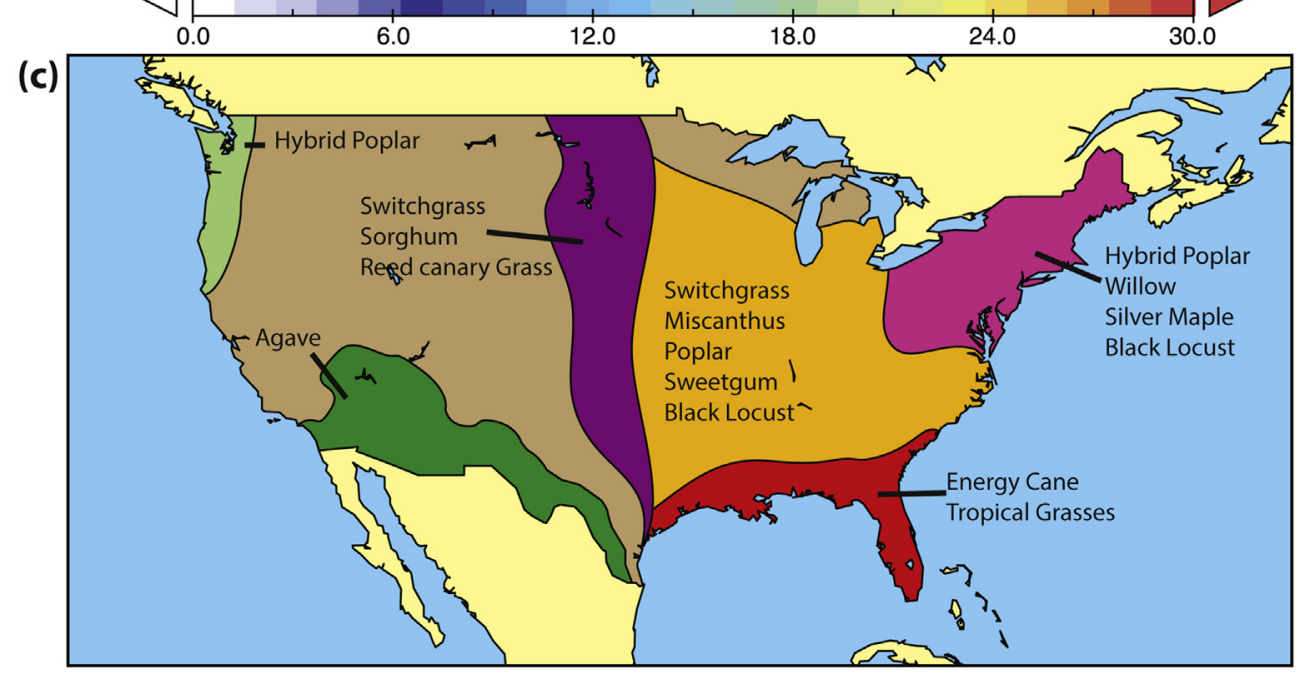

Fig. 3 - US climatological June-August precipitation (a) and temperature (b) from CRU dataset [110]. Climatology is defined here as the mean of 1961-1990. Also shown is a map of approximate locations where potential bioenergy agroecosystems may be adopted in the US (c) (adapted from Department of Energy map [111]). The states outlined in red in (b) represent the Midwest United States for the purposes of this study, and the coast outlined in white denotes the Gulf Coast. (For interpretation of the references to color in this figure legend, the reader is referred to the web version of this article.) 
Crassulacean Acid Metabolism (CAM) photosynthetic pathway, distinguished by exceptional water use efficiency (WUE). Recent research on the suitability of bioenergy production in the region has focused on the genus Agave, a group of obligate CAM plants that have been grown commercially in this and other semi-arid parts of the world [27]. Similarly, in other regions of the globe, including East Asia and Africa, analyses have been done to understand the suitability of local lands to bioenergy expansion [28-30].

Abandoned cropland that has been classified as 'marginal' is being specifically studied for bioenergy expansion $[4,20,21]$. In the US alone, it has been estimated that there are between 40 and 68 Mha of abandoned cropland, although $\sim 2$ Mha of that has been converted to urban areas, and $\sim 21$ Mha (largely in the Northeast US) has undergone afforestation [21]. The approach of targeting abandoned cropland reduces the potential for indirect land use change by minimizing the competition between bioenergy and food agro-ecosystems for available arable land [31]. Additional opportunities, such as double-cropping and utilizing harvest residue, exist to expand bioenergy production within our existing agricultural infrastructure [32,33]. However, the long-term sustainability and impacts of these practices on ecosystem services, including biophysical regulation of water and climate, must first be established [4,34].

\section{Biophysical feedbacks of vegetation on climate: the role of the surface energy budget}

The biophysical feedbacks between vegetation, water, and climate in agro-ecosystems occur across a continuum of spatial scales. While key processes spanning spatial scales are detailed below, many of the impacts manifest themselves as perturbations to the SEB. Net radiant energy available at the surface $\left(R_{n} ; \mathrm{W} \mathrm{m}^{-2}\right)$, which is defined as the sum of net surface solar and terrestrial radiation, regulates the energetics of evapotranspiration and is expressed as:

$R_{\mathrm{n}}=\mathrm{S}(1-\alpha)+L_{\mathrm{w}}-\varepsilon \sigma \mathrm{T}^{4}$

where $S$ is incoming solar radiation $\left(\mathrm{W} \mathrm{m}^{-2}\right), \alpha$ is albedo (the integrated reflectance of the surface over the shortwave and near-infrared regions of the electromagnetic spectrum; unitless), $L_{\mathrm{w}}$ is incoming longwave radiation $\left(\mathrm{W} \mathrm{m}^{-2}\right), \varepsilon$ is surface emissivity (unitless), $\sigma$ is the Stefan-Boltzmann constant $\left(5.67 \times 10^{-8} \mathrm{~W} \mathrm{~m}^{-2} \mathrm{~K}^{-4}\right)$, and $\mathrm{T}$ denotes surface temperature (K). $R_{n}$ is partitioned into sensible $\left(H ; \mathrm{W} \mathrm{m}^{-2}\right)$, latent $\left(L ; \mathrm{W} \mathrm{m}^{-2}\right)$, and ground $\left(G ; \mathrm{W} \mathrm{m}^{-2}\right)$ heat fluxes as:

$R_{\mathrm{n}}=\mathrm{H}+\mathrm{L}+\mathrm{G}$

$H$ represents the direct exchange of energy between the earth's surface and the atmosphere by convection or conduction, and $G$ is the conductance of heat into or out of the soil. Finally, $L$ is the flux of energy between the surface and atmosphere through the evaporation of water and is directly related to evapotranspiration:

$L=\lambda \cdot E T$

where $\lambda$ is the latent heat of vaporization $\left(\mathrm{J} \mathrm{mol}^{-1}\right.$ or $\left.\mathrm{J} \mathrm{kg}^{-1}\right)$ and ET is evapotranspiration ( $\mathrm{mol} \mathrm{m}^{-2} \mathrm{~s}^{-1}$ or $\mathrm{kg} \mathrm{m}^{-2} \mathrm{~s}^{-1}$ ).
The partitioning of $R_{n}$ into sensible, latent, and ground heat fluxes is strongly influenced by the presence and variation of vegetation, which may tap into reservoirs of stored soil water. The correct representation of $R_{n}$ and its partitioning is essential for diagnosis of land-atmosphere impacts and assessment of vegetation-climate impacts across the spectrum of spatial and temporal scales $[7,35]$. Differences in vegetative covers (e.g., forest or agriculture), including those associated with variations in bioenergy crop type, are characterized by variability in biophysical parameters (e.g., albedo,
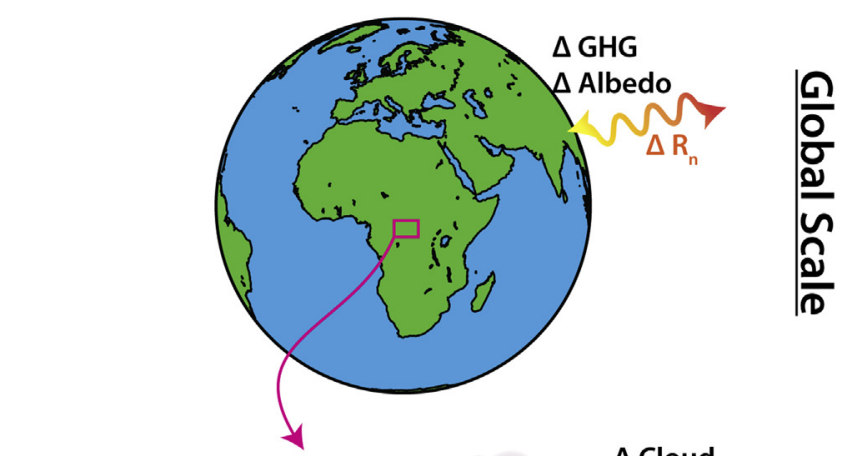

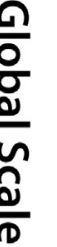
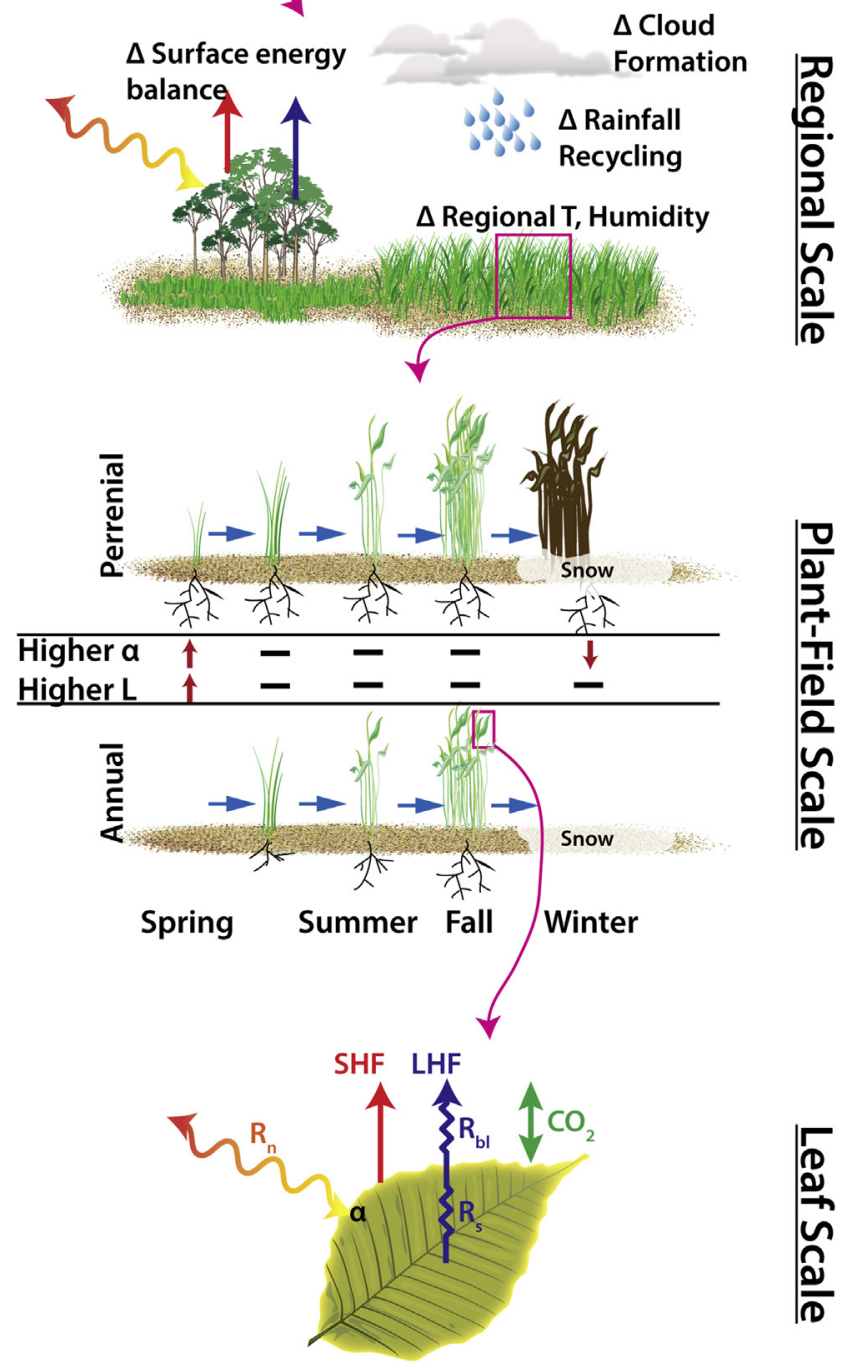

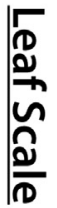

Fig. 4 - Schematic of major impacts of bioenergy adoption occurring at leaf to global scales as described in Section 4. 
leaf area index [LAI], canopy architecture, rooting depth, photosynthesis physiology etc.) that affect both $R_{n}$ and its partitioning. In modern land surface models the variability in biophysical parameters is poorly constrained for most ecosystems, leading to uncertainty in the representation of vegetation [36,37]. For novel bioenergy agro-ecosystems this uncertainty is amplified by the lack of measurements of key biophysical parameters tied to parameterizations of photosynthetic capacity, stomatal conductance, respiration, and plant carbon allocation.

\section{Scales of vegetation-climate interaction}

The biophysical interaction between bioenergy crops and climate occurs within the atmospheric boundary layer and is defined by the nature of the land surface. There are a variety of processes by which plants can interact with climate. These processes operate across a spectrum of spatial and temporal scales from the leaf to the globe (Fig. 4). This section separates the spatial spectrum of processes into leaf, plant/field, regional, and global categories, and reviews important vegetation-climate interactions occurring at each scale. These categories are meant to be useful as an illustrative concept and not imply that the processes occurring at each scale are mutually exclusive.

\subsection{Leaf scale}

At the leaf surface, the partitioning of energy is analogous to the land surface balance given in Equation (2), with net absorbed/emitted radiation at the leaf surface balanced by latent and sensible heat fluxes (Fig. 4). An estimate of the latent and sensible heat fluxes between the leaf and atmosphere can be represented by:

$H_{\text {leaf }} \approx c_{p} g_{h}\left(T_{l}-T_{a}\right)$,

$L_{\text {leaf }} \approx \lambda g_{\mathrm{v}} \frac{e_{\mathrm{s}}\left(\mathrm{T}_{\mathrm{l}}\right)-e_{\mathrm{a}}}{p_{\mathrm{a}}}$

where $c_{\mathrm{p}}$ is the specific heat of air $\left(\mathrm{J} \mathrm{mol}^{-1} \mathrm{~K}^{-1}\right.$ or $\left.\mathrm{J} \mathrm{kg}^{-1} \mathrm{~K}^{-1}\right), \mathrm{T}_{\mathrm{L}}$ is leaf temperature $(\mathrm{K}), \mathrm{T}_{\mathrm{a}}$ is the air temperature $(\mathrm{K}), e_{\mathrm{s}}$ and $e_{\mathrm{a}}$ are vapor pressures at the leaf surface and in the air $(\mathrm{kPa}), p_{\mathrm{a}}$ is atmospheric pressure $(\mathrm{kPa})$ [38]. $g_{\mathrm{h}}$ and $g_{\mathrm{v}}$ represent leaf conductances ( $\mathrm{mol} \mathrm{m} \mathrm{m}^{-2} \mathrm{~s}^{-1}$ or $\mathrm{mm} \mathrm{s}^{-1}$ ) of heat and water respectively. It is useful to consider the leaf conductance of water as the conductance of water through the leaf boundary layer in series with the conductance of water through the leaf stomata:

$g_{\mathrm{v}}=\frac{g_{\mathrm{s}} g_{\mathrm{bl}}}{g_{\mathrm{s}}+g_{\mathrm{bl}}}$

where $g_{\mathrm{bl}}$ is the leaf boundary layer conductance to water vapor, and $g_{\mathrm{s}}$ is the leaf's stomatal conductance of water vapor.

Stomatal conductance is the key linkage between plants and climate at the leaf scale. Stomata exert control over the exchange of water, energy, and carbon between leaves and their environment and are fundamental drivers for significant environmental change [38-40]. Under photosynthetic conditions, stomata allow inward diffusion of $\mathrm{CO}_{2}$, which is used as a substrate for photosynthesis, while allowing water to exit the leaf.

Stomata respond to a wide range of environmental conditions including light, humidity, $\left[\mathrm{CO}_{2}\right]$, and to a lesser extent temperature [40]. Stomatal conductance is linked to leaf photosynthesis, which itself is highly responsive to the environment [39]. Although we do not currently have a complete physical understanding of stomatal regulation, the predictable means by which stomata respond to the environment led to the development of an empirical model $([40,41])$ that explicitly links transpiration and the assimilation of $\mathrm{CO}_{2}$ and implicitly links water and energy at the leaf-scale:

$g_{\mathrm{s}}=\frac{m A_{\mathrm{n}} h_{\mathrm{s}}}{c_{\mathrm{s}}}+b$

where $g_{s}$ is the stomatal conductance to water vapor, $A_{n}$ is the net rate of carbon assimilation into the leaf, $c_{s}$ is the concentration of $\mathrm{CO}_{2}\left(\left[\mathrm{CO}_{2}\right]\right)$ at the surface of the leaf, $h_{\mathrm{s}}$ is the relative humidity of air at the leaf surface, and $m$ and $b$ are stomatal slope and intercept parameters that are typically unique to individual plant species. This seemingly simple relationship belies the complexity of the role stomatal conductance plays in determining the feedbacks between vegetation and climate.

The importance of stomata in regulating the partitioning of net radiation into latent and sensible heat flux and the responses of stomata, including its variation, to the environment are all factors that warrant consideration when land use changes lead to a transition from one vegetation type to another. An analogy of the influence that changes in stomata can play at the landscape level is linked to the gradual increase in atmospheric $\mathrm{CO}_{2}$. As described in Equation (7), rising $\left[\mathrm{CO}_{2}\right]$ leads to a decrease in stomatal conductance. If this decrease in stomatal conductance alters the SEB, the gradual increase in atmospheric $\left[\mathrm{CO}_{2}\right]$ since the start of the industrial revolution should have resulted in decreased evapotranspiration. Some analyses have shown that this response of stomata is a major driver for increased water discharge from major watersheds in the US, although subsequent studies have increased the uncertainty of this effect [42-44]. While Gedney et al. ([42]) linked the increase in surface flow of water to stomata, mass balance dictates that this increased flow is directly tied to less evapotranspiration and higher sensible heat fluxes (e.g. [45]) that directly influence climate through biophysical feedbacks. Similarly, planting bioenergy crops with altered stomatal responses relative to the existing vegetation is likely to perturb the feedbacks between leaf stomata and climate in much the same manner, although not necessarily to the same degree or in the same direction.

There exists a large body of scientific research on the feedbacks between leaf physics and climate (e.g. Refs. [40,41]). However, important questions remain, including: (1) How variable are the species-specific parameters, such as those used in Equation (7), for various potential bioenergy feedstocks and how might they differ from the vegetation they replace? (2) How do species-specific leaf responses scale up to water use and energy partitioning at the canopy and/or ecosystem scale? (3) To what extent is the ratio of crop yield to water usage regulated by stomatal conductance and how can that inform the suitability of a crop for a given region? 


\subsection{Plant-field scale}

There are a variety of processes that can influence the linkages between vegetation and climate that occur at the plant and field scale. Plant canopies absorb and partition energy differently throughout their growing season due to changes in plant specific radiative properties, canopy architecture, and physical size. This can contribute to differences in the SEB between crop types. The differences in SEB can be particularly acute when considering shifts in land use to bioenergy agroecosystems where plants are commonly selected for high rates of carbon assimilation and overall yield [25]. These differences are complicated by the fact that the partitioning of energy not only changes seasonally and between vegetation types, but also within a plant canopy itself where substantial changes in microclimate occur.

Characteristics such as plant structure and albedo determine the available radiation throughout the canopy and at the soil surface. Small changes in overall plant albedo can add up to significant alterations in the field energy balance. For most ecosystems, albedo varies between $~ 10 \%$ and $35 \%$, which causes a direct impact on $R_{n}$ and therefore influences the total energy available to be partitioned into fluxes of energy and moisture [7]. The albedo of an agricultural ecosystem is closely tied to phenology, canopy architecture, and field row spacing. Plant specific processes and characteristics such as leaf angle and the development of reproductive structures can influence plants' radiative properties and alter the surface albedo. However, the interplay between crop management and crop phenology may have a larger influence on the annual balance of $R_{n}[14,46]$.

With emergence and an increase in LAI, the fraction of soil exposed to direct radiation decreases, and overall surface albedo increases (Fig. 4) [47]. Using the Midwestern US as an example, there is a stark contrast in $R_{n}$ between areas planted with row-crops and areas dominated by deciduous trees. This contrast is particularly strong during and after snow events in late Fall to early Spring when relatively dark bare trees present a brown, lower albedo surface to incoming radiation than the barren, snow-covered, high albedo surface of row-crop fields. This leads to forested areas absorbing $40 \%$ more radiation during the winter [48]. The barren crop fields absorbing significantly less energy during the winter can potentially lower $\mathrm{H}$ in the SEB (Equation (2)) and cool the local air.

After plants reach maturity, the LAI and albedo tend to decrease as leaves senesce. Many of the promising bioenergy crops for the region, including perennial grasses, have longer growing seasons than traditional crops (e.g. maize and soybean). The grasses emerge before traditional crops, and are harvested later in the year, possibly after snow events have likely occurred. This may lead to significant annual radiative differences between traditional and advanced energy crops, although additional work is needed to quantify the magnitude of these effects.

Water use also varies due to plant development and phenology. Because of rooting depth differences, annual crops at their early stages of development typically transpire less water relative to a mature perennial crop and potentially retain more soil moisture. Consequently, because of perennials' ability to tap into available water reservoirs at greater depths below the surface, larger fluxes of moisture are expected for perennial grasses relative to that of annual crops, with important implications for the spatial distribution of surface heating (Fig. 4). Longer growing seasons also contribute to greater fluxes of water $[49,50]$.

Several field-scale studies have highlighted the influence that planting bioenergy crops may have on $R_{n}$ and the SEB. For example, recent work over Brazil used satellite data to examine the impact of vegetation on influencing temperature, $L$, and albedo over land transitioning from natural cerrado (i.e., savanna) to a pasture/crop mix to sugarcane [12]. The transition of pasture to sugarcane led to a small increase in albedo, an increase in ET, and a decrease in local temperature highlighting the influence that adoption of bioenergy crops may have on regional climate. Similarly, on an annual basis, important field-scale differences were observed between traditional annual crops and advanced energy crops in the Midwest US, with miscanthus and switchgrass transpiring more water over a growing season than maize largely due to a longer season $[18,50]$.

Historical and empirical knowledge of crops currently being studied for utilization as advanced bioenergy feedstocks is lacking relative to many traditional agro-ecosystems. As a result there remain many important plant-field scale questions that require examination including: (1) How do the dynamics of SEB change based on transitioning from one species to another, including factors that extend beyond the growing season such as residue cover and standing biomass? (2) How do extreme events impact bioenergy crops and their associated feedbacks on climate? (3) How does climate dictate the phenological stage of a bioenergy crop, and how will plant development change with increasing greenhouse gasses? (4) To what extent do smaller scale leaf-climate interactions express themselves at the plant-field scale? (5) How may plant engineering influence the suitability and climate feedbacks of a bioenergy crop for a region?

\subsection{Regional scale}

At the regional scale the interplay between climate and land cover is complex and intertwined with natural climate oscillations, as well as changes in regional temperature and precipitation associated with increased GHG emissions. However, recent research has identified several key connections between surface land cover and regional climate that are relevant for changing land use associated with bioenergy expansion.

Regional climate and vegetation are linked through surface fluxes of energy, moisture, and carbon in the atmospheric boundary layer. Large-scale shifts in vegetation, such as that potentially associated with bioenergy crop adoption, can result in regional redistribution of the $H$ and $L$ components of energy fluxes between the land surface and the atmosphere (Fig. 4). These shifts in surface fluxes directly perturb the state of the atmospheric boundary layer and subsequently regional climate. For example, potential bioenergy crops are expected to increase albedo and transpiration relative to existing vegetation in the Midwestern US. This has been projected to lead to regional decreases in surface air temperature of $1-2{ }^{\circ} \mathrm{C}$ [5]. Additionally a cooler, moister boundary layer may lead to perturbations in the regional hydrological cycle through 
changes in soil moisture, precipitation, and the suppression or enhancement of clouds [13,14,51-55]. Finally, expansion of bioenergy agro-ecosystems may lead to regional changes in the use of irrigation. Multiple studies have illustrated the impact that irrigation has on surface energy budgets and regional climate (e.g. Refs. [56-58]).

Differential heating due to regional contrasts in land use associated with agricultural management decisions (e.g., irrigated agriculture with greater ET relative to dry-land agriculture) can initiate mesoscale $(1-100 \mathrm{~km})$ atmospheric circulations similar to sea breezes $[59,60]$. Such circulations form narrow updraft zones, transport moist air from adjacent patches, and can result in increased local convective rainfall (e.g. [61]). The magnitude and distribution of vegetation have consequences for direct transport of heat and energy into the atmosphere, the triggering of organized convection (and potentially, enhancement of existing systems), and modification of larger-scale atmospheric dynamics [62].

An important indicator of regional land-atmosphere coupling is the rainfall recycling ratio, or the fraction of precipitation within a region that evaporated off the earth's surface within the region itself. The strength of land-atmosphere coupling and the magnitude of the rainfall recycling ratio are influenced by many factors, including circulation, atmospheric stability, and regional vegetation $[35,63]$. As described above, heterogeneous patterns of vegetation can alter atmospheric stability and preferentially initiate precipitation over particular regions. Also, altering regional cover may perturb the $L$ of a region and modify the regional recycling ratio. For example, in the Great Plains of the United States portions of land cover consist of irrigated crops with high L. Great Plains irrigation was shown to lead to increased regional precipitation and increased regional recycling ratios [64]. Replacing these crops with more water efficient bioenergy crops not requiring irrigation could lower $L$ and alter rainfall recycling in the region. However, these feedbacks are regionally dependent on mesoscale atmospheric dynamics, and in some regions increasing $L$ may inversely influence precipitation (e.g. Refs. [51,52,65-68]).

Extreme hydrological conditions associated with drought and flood are typically considered regional-scale phenomena. Understanding the resilience of bioenergy crops to changes in the frequencies of these conditions will be vital for understanding the climate benefits and long-term sustainability of a feedstock for a given region. Additional questions that need to be regionally addressed include: (1) To what extent can land use modify regional temperatures, moisture transport and storage in the soil and atmosphere, and atmospheric stability? (2) In a given region are perturbations to the hydrological cycle important to maintaining sustainable surface water balance? (3) How will changes in climate due to GHG's alter the suitability of a region for a given bioenergy crop? (4) How do fluxes of moisture, carbon, and energy between bioenergy crops and the atmospheric boundary layer respond to future climate, and will the biophysical impacts of bioenergy crop expansion improve or degrade regional growing conditions?

\subsection{Global scale}

At the global scale, the climate and water systems are largely a closed system. As such, biophysical perturbations associated with land use change may have global-scale non-local effects. Such effects can occur through changing atmospheric or oceanic circulation and indirect effects associated with cloud formation $[69,70]$. However, the impacts of bioenergy expansion on a global-scale are likely to be dominated by biogeochemical processes that influence the atmospheric GHG concentrations. One of the primary motivations for the expansion of advanced bioenergy agroecosystems is the potential for reductions in GHG emissions relative to current liquid fuel options. Therefore a fundamental question that must be addressed at the global-scale is: Can large-scale establishment of bioenergy agro-ecosystems mitigate changes in climate due to GHG emissions while maintaining necessary food production and minimizing environmental degradation? Additionally, there is a question of time relevance. As land is converted to bioenergy crops an initial pulse of GHG emissions usually, although not always, occurs [31,71-75]. For some landscapes it has been estimated that balancing this initial GHG pulse through mitigated emissions could take $>100$ years [72,74]. At what timescale is the payback of this initial GHG pulse through mitigated emissions useful to society and to what extent can biophysical influences of land cover change reduce or extend this payback time through changes in albedo and surface energy partitioning? Finally, what techniques and what combinations of bioenergy crops and existing ecosystems can be utilized to minimize the initial GHG pulse associated with establishing a new crop?

Advanced bioenergy agroecosystems will be developed in a continuously changing climate, with increasing atmospheric $\left[\mathrm{CO}_{2}\right]$, as well as other greenhouse gases, temperature, and hydrological variability likely. Modified atmospheric composition may redefine the viable spatial extent of a given bioenergy crop, but also the risk associated with extreme climate and weather, plant disease, and pests. Determining how these risks change with time will be vital to sustainable bioenergy development.

\section{Tools needed to address climate feedbacks in bioenergy agro-ecosystems}

As described in the previous section the net feedback between climate and vegetation is the result of varied effects over a large range of spatial and temporal scales. This limits the usefulness of any single tool for assessing the biophysical climatic impact of converting land to a bioenergy agroecosystem. Instead, a variety of observational techniques and computational models have been developed to understand the impacts of land use change.

\subsection{Common tools currently in use}

\subsubsection{Brief history of advances}

Early pioneering work assessing albedo-induced impacts of desertification in the Sahel found considerable reduction in cloud cover and associated rainfall that could occur from excessive overgrazing [76]. The tools utilized, in their early stages of development, paved the way for more sophisticated representation of land surface processes while also 
emphasizing the critical need for remotely sensed monitoring of relevant biophysical properties.

Initial representation of sensible $(H)$ and latent $(L)$ heating in first-generation land surface models (LSMs), was treated as a quasi-diffusive process. $G$ was omitted, and repartitioning into $H$ and $L$ was idealized via usage of a constant soil waterholding capacity (the so-called "bucket model" parameterization), wherein exceeding a prescribed limit in the bucket was treated as runoff [77]. 2nd generation models improved upon the passive first-generation approach by accounting for soil and vegetative treatment, incorporating spatial albedo variability and accounting for the dependency of canopy insolation absorption upon differential wavelengths (i.e., different absorption spectra for photosynthetically active radiation relative to the near-infrared) [77]. A further advancement was the improved representation of evapotranspiration through dependence on stomatal conductance (Equation (7)) and the inclusion of key biophysical parameter control (e.g., LAI) on ET. Treatment of soil moisture processes added complexity via vertical transfer through the soil column and inclusion of soil texture dependent characteristics (e.g., hydraulic conductivity). Finally, development of thirdgeneration models was greatly enhanced by recognizing the importance of $\mathrm{CO}_{2}$ assimilation, allowing for the representation of plant carbon uptake and simulation of the carbon cycle $[6,77]$.

\subsubsection{Model implementation}

Spatially explicit, seasonally varying green vegetation fraction and LAI are necessary inputs for modern-day LSMs. Satellitederived metrics impose boundary conditions that have become instrumental for proper treatment of the SEB in LSMs [78], which have played a central role toward improved understanding of land-atmosphere interactions. For example, Weaver and Avissar [79], used observations and a LSM coupled to an atmospheric model to show that thermally induced circulations, driven by landscape heterogeneity owing to agricultural practices, produce diurnal circulations whose impacts extend beyond local scales.

Advances in the modeling of land-atmosphere coupling, improved representation of physical land surface processes, increased computing resources and associated resolution enhancement have led to considerable recent progress in the utility of both offline [11] and coupled LSM-atmospheric models $[6,13,54,80]$ for the examination of hydroclimatic consequences owing to biofuel expansion. Much of this work has relied on in-situ observations for the parameterization of crop types within a numerical modeling framework, highlighting the dual importance of process-based modeling and field measurements.

\subsection{Limitations of current tools; key uncertainties introduced}

\subsubsection{Diagnostic us. prognostic parameterizations}

Significant progress has been made toward understanding the implications of land use change on climate. However, limitations inherent in the representation of fundamental processes in earth system models remain. One key example is the inability to resolve the physiological and phenological responses to anomalous environmental conditions. The current generation of LSMs used in climate models typically requires that the development of LAI, the onset of growth, and senescence (i.e. phenology) be prescribed as set parameters in the model, based on historical observations or slight modifications to these observations (e.g. Ref. [5]). However, the onset of growth and senescence is a factor that can vary interannually. Another limitation of prescribing vegetative characteristics such as LAI, root biomass and rooting depth is that anomalous conditions (e.g. drought, heat wave, flooding) can significantly alter canopy carbon uptake and development through physiological response, which can consequently modify the value of these important parameters for canopy-atmosphere exchange. Finally, most LSM's currently only include one or two generic crop types that do not necessarily represent the unique properties that many bioenergy crops exhibit. This often limits their usefulness in assessing crop-specific biophysical impacts on moisture and energy fluxes.

The limitations of LSM's to represent biophysical impacts of land use on water and climate have been recently illustrated in the Land-Use and Climate, Identification of Robust Impacts (LUCID) project $[81,82]$. This project was designed to test the magnitude of impact that past land use change has had on climate, and used a series of seven coupled landatmosphere models with similarly imposed land use change. Initial results were inconclusive with minimal consistency between the model's partitioning of the surface energy balance at specific times [81]. They concluded that this inconsistency was due in large part to differing parameterizations of albedo, crop phenology, and evapotranspiration, and pointed to the need for improved evaluation of LSMs [82].

\subsubsection{Uncertainties in response to environmental variability} Global change factors (increasing temperature, $\mathrm{CO}_{2}$ and $\mathrm{O}_{3}$, and shifts in precipitation regimes) are likely to have a significant impact on feedbacks between land use change and climate. Experiments at Free Air $\mathrm{CO}_{2}$ Enrichment (FACE) sites have tested the impacts of these global change factors on crop growth. These experiments have found that growth at elevated $\mathrm{CO}_{2}$ and $\mathrm{O}_{3}$ has been shown to alter the exchange of carbon and energy from crop canopies (e.g. Refs. [83,84]), a factor that is rarely included in land-use-change studies [85] especially at regional scales [48]. This is further complicated by the varied response of plant species to changing climate and pollutant concentrations. Differences in vegetation-climate interactions among plant species may be drastically different in a future climate. Increasing temperature can alter carbon uptake by crops [86] as well as vapor pressure deficit if not met by complementary increases in specific humidity. A full review of FACE results are beyond the scope of this study, and has been reviewed previously [87].

Because future bioenergy production is expected to occur on sub-optimal land [21], it will also be crucial to understand the impacts of small-scale variation in soil quality and land surface slope on canopy-atmosphere exchange [88]. Another factor that can have a major influence on land surface properties and exchange is management. The timing of planting and harvest as well as tillage and irrigation regimes can have a profound effect on carbon and energy fluxes [17] [89]. 


\subsubsection{Model evaluation with measurements}

Resolving the impact of uncertainties on the representation of climate-land use change feedbacks will require a network of measurements of key multi-scale processes at a range of locations. Measurements of $L, H$, and $R_{n}$ coupled with subsurface runoff and atmospheric boundary layer observations of temperature and humidity are necessary to constrain model predictions across the soil-vegetation-atmosphere continuum. Leaf level measurements are also required, as processes at this scale are the major drivers for the fluxes that impact vegetation-climate feedbacks. Also, satellite products can play increasingly important roles in assessing vegetation-climate feedbacks as new sensors and algorithms allow for previously unavailable large-scale analysis of key biophysical parameters [90]. In addition to covering the range of spatial scales and processes listed here, it is important that observations are taken in a wide enough range of environmental conditions (e.g. soil type and climate variations) to ensure simulations are able to represent observations across the full range of variation. This level of high quality observations will be necessary for each feedstock type and growing region to properly quantify the role of land use change for bioenergy on influencing the vegetation-water-climate feedback system.

The addition of novel observations will help constrain our understanding of uncertainty in LSMs. However, new tools are also being developed to synthesize this data into models and improve the metrics by which these models are evaluated in order to accelerate model improvements and target observations needed to reduce model uncertainty [37,91-93]. These complementary emerging techniques depend on developing metrics that assess the extent by which parameter uncertainty influences overall model uncertainty, and estimating the degree by which models are independent of one another. By incorporating this information into future analyses we will improve model representations of the land surface and better characterize the uncertainty associated with modeling feedbacks between land use and climate.

\subsubsection{Moving targets (policy and biotech advances)}

The evolving nature of the emerging bioenergy industry also presents major challenges to accurately quantifying vegetation-climate feedbacks. Policy at national, state, and local levels driving bioenergy expansion is likely to be modified within the life span of a biorefinery (ca. 30 years). Meanwhile, biotechnical advances are likely to produce novel cultivars or hybrids of feedstocks that could significantly change the initial predictions of study, with changes in productivity intimately tied to canopy-atmosphere exchange. While there are numerous limitations and challenges associated with the current state of the science of climate feedbacks associated with land use change, the body of research conducted to date has laid the foundation for a new generation of tools and advances that have potential to provide great insight.

\subsection{Necessary tools and expected advances}

To perform end-to-end analyses of environmental impacts and ecosystem services of land use associated with biofuel production, it is necessary to examine the coupled feedbacks of the land-atmosphere system within a dynamically evolving climate model framework. Shared community models are available (e.g., the Weather Research and Forecasting model (WRF); [94]) that incorporate well-vetted atmospheric radiation, cloud, and precipitation physics packages. However, typically lacking in the coupled land-atmosphere models are physical process representations of crop dynamics, biogeochemical interactions, and water and energy flows through crops into the surface. These deficiencies must be addressed to simulate the dynamically coupled effects of land use change in crop ecosystems. For example, operational LSMs in WRF do not have plant type representations consistent with the growing season or biophysical responses of cellulosic biofuel feedstocks $[5,80]$. The limited prescription of vegetation physics in models such as WRF cannot represent the dynamics of crop senescence associated with hydrologic extremes [95]. Other regional models have begun to move beyond static vegetation representations, but these dynamic vegetation representations are not yet in wide use. In addition, irrigation and natural lateral flows of surface and groundwater are also inadequately represented in regional climate models. The development of such systems with improved physical processes is needed (e.g. [96-98]).

To assess the coupled nature of land-atmosphere feedbacks associated with biofuel feedstocks, climate modeling systems must more accurately represent the vegetation dynamics and biogeochemical processes of biofuel and other natural and agricultural feedstocks, vetted with observational data of water, energy, greenhouse gas, and nutrient fluxes (e.g. $[99,100])$. In addition, hydrologic models in regional climate models require inclusion of surface and below-ground lateral transports and storage of water [101]. The spatial resolution of models used to study these processes must be fine enough both to accurately simulate clouds and precipitation, and also represent realistic spatial patterning of landatmosphere interaction known to modulate atmospheric flows, clouds, and rainfall $[100,102]$, on the order of a few kilometers or less. Finally, in addition to expansion of site measurements, improved remote sensing data and data assimilation tools must be used for initialization and quantitative evaluation of model improvements (e.g. $[103,104])$.

\section{Outlook}

Adopting new bioenergy agro-ecosystems and improving existing practices will require careful assessment of how potential feedstocks will influence ecosystem services. This assessment will require advanced knowledge of the biophysical and biogeochemical vegetation-climate feedbacks that bioenergy crops experience at a variety of scales. However, as outlined above there remain open questions that need to be addressed to improve our understanding of how bioenergy crops will interact with climate at many scales. Improved computational and observational tools are necessary in order to accurately address open questions of vegetation-climate feedbacks.

Improved understanding of vegetation-climate interactions can lead to enhanced capabilities to optimize the 
selection of a feedstock or variety of feedstocks for a given region. This will have both political and economic value as risks associated with developing a nascent bioenergy market can be reduced, and open questions can be answered to ensure secure investment and ecologically sustainable growth.

\section{Acknowledgments}

This work was funded by the Energy Biosciences Institute (JEB, CJB, SD, MZH, JM, AV) and MG was supported by NSF Grant EAR-1204774.

\section{R E F E R E N C E S}

[1] Ramankutty N, Evan AT, Monfreda C, Foley JA. Farming the planet: 1. Geographic distribution of global agricultural lands in the year 2000. Glob Biogeochem Cycles 2008;22:GB1003. http://dx.doi.org/10.1029/2007GB002952.

[2] Searchinger T, Heimlich R, Houghton RA, Dong F, Elobeid A, Fabiosa J, et al. Use of U.S. croplands for biofuels increases greenhouse gases through emissions from land-use change. Science 2008;319:1238-40.

[3] Davis SC, Parton WJ, Del Grosso SJ, Keough C, Marx E, Adler PR, et al. Impact of second-generation biofuel agriculture on greenhouse-gas emissions in the corngrowing regions of the US. Front Ecol Environ 2012;10:69-74.

[4] Gelfand I, Sahajpal R, Zhang X, Izaurralde RC, Gross KL, Robertson GP. Sustainable bioenergy production from marginal lands in the US Midwest. Nature 2013;493:514-7.

[5] Georgescu M, Lobell DB, Field CB. Direct climate effects of perennial bioenergy crops in the United States. Proc Natl Acad Sci USA 2011;108:4307-12.

[6] Sellers PJ, Dickinson RE, Randall DA, Betts AK, Hall FG, Berry JA, et al. Modeling the exchanges of energy, water, and carbon between continents and the atmosphere. Science 1997;275:502-9.

[7] Pielke RA. Influence of the spatial distribution of vegetation and soils on the prediction of cumulus convective rainfall. Rev Geophys 2001;39(2):151-77.

[8] Somerville C, Youngs H, Taylor C, Davis SC. Long SP feedstocks for lignocellulosic biofuels. Science 2010;329:790-2.

[9] Robertson GP, Dale VH, Doering OC, Hamburg SP, Melillo JM, Wander MW, et al. Sustainable biofuels redux. Science 2008;322:49-50.

[10] Davis SC, Kucharik CJ, Fazio S, Monti A. Environmental sustainability of advanced biofuels. Biofuels Bioprod Bioref 2013;7(6):638-46.

[11] VanLoocke A, Bernacchi CJ, Twine TE. The impacts of Miscanthus x giganteus production on the Midwest US hydrologic cycle. GCB-Bioenergy 2010;2:180-91.

[12] Loarie SR, Lobell DB, Asner GP, Mu Q Field CB. Direct impacts on local climate of sugar-cane expansion in Brazil. Nat Clim Change 2011;1:105-9.

[13] Georgescu M, Lobell DB, Field CB, Mahalov A. Simulated hydro-climatic impacts of projected Brazilian sugarcane expansion. Geophys Res Lett 2013;40:972-7.

[14] Tölle MH, Gutjahr O, Busch G, Thiele JC. Increasing bioenergy production on arable land- does the regional and local climate respond? Germany as a case study. J Geophys Res 2014. http://dx.doi.org/10.1002/2013JD020877.
[15] Baldocchi D, Falge E, Gu L, Olson R, Hollinger D, Running S, et al. FLUXNET: a new tool to study the temporal and spatial variability of ecosystem-scale carbon dioxide, water vapor, and energy flux densities. Bull Am Meteor Soc 2001;82:2415-34.

[16] Sartori F, Lal R, Ebinger MH, Parrish DJ. Potential soil carbon sequestration and $\mathrm{CO}_{2}$ offset by dedicated energy crops in the USA. Crit Rev Plant Sci 2006;25:441-72.

[17] Davis SC, Boddey R, Alves B, Cowie A, George B, Ogle SM, et al. Management swing potential for bioenergy crops. GCB Bioenergy 2013;5(6):628-38.

[18] Zeri M, Hussain MZ, Anderson-Teixeira KJ, DeLucia EH, Bernacchi CH. Water use efficiency of perennial and annual bioenergy crops in central Illinois. J Geophys Res Biogeosci 2013;118:581-9.

[19] Hoogwijk M, Faaij A, Eickhout B, de Vries B, Turkenburg W. Potential of biomass energy out to 2100 , for four IPCC SRES land-use scenarios. Biomass Bioenergy 2005;29(4):225-57.

[20] Cai X, Zhang X, Wang D. Land availability for biofuel production. Environ Sci Technol 2011;45(1):334-9.

[21] Zumkehr A, Campbell JE. Historical U.S. cropland areas and the potential for bioenergy production on abandoned croplands. Environ Sci Technol 2013;47:3840-7.

[22] Wright CK, Wimberly MC. Recent land use change in the Western Corn Belt threatens grasslands and wetlands. Proc Natl Acad Sci U S A 2013;110(10):4134-9.

[23] Nemani RR, Keeling CD, Hashimoto H, Jolly WM, Piper SC, Tucker CJ, et al. Climate-driven increases in global terrestrial net primary production from 1982 to 1999. Science 2003;300(5625):1560-3.

[24] Hohenstein WG, Wright LL. Biomass energy production in the United States: an overview. Biomass Bioenergy 1994;6(3):161-73.

[25] Heaton EA, Dohleman FG, Long SP. Meeting US biofuel goals with less land: the potential of Miscanthus. Glob Change Biol 2008;14:2000-14.

[26] Wortmann CS, Liska AJ, Ferguson RB, Lyon DJ, Klein RN, Dweikat I. Dryland performance of sweet sorghum and grain crops for biofuel in Nebraska. Agron J 2010;102:319-26.

[27] Davis SC, Dohleman FG, Long SP. The global potential for Agave as a biofuel feedstock. GCB Bioenergy 2011;3:68-78.

[28] Ndong R, Montrejaud-Vignoles M, Saint Girons O, Gabrielle B, Pirot R, Domergue M, et al. Life cycle assessment of biofuels from Jatropha curcas in West Africa: a field study. GCB Bioenergy 2009;1(3):197-210.

[29] Black E, Vidale PL, Verhoef A, Cuadra SV, Osborne T, Ven den Hoof C. Cultivating C4 crops in a changing climate: sugarcane in Ghana. Environ Res Lett 2012;7:044027.

[30] Liu W, Sang T. Potential productivity of the Miscanthus energy crop in the Loess Plateau of China under climate change. Environ Res Lett 2013;8:044003. http://dx.doi.org/ 10.1088/1748-9326/8/4/044003.

[31] Gelfand I, Zenone T, Jasrotia P, Chen J, Hamilton SK, Robertson GP. Carbon debt of Conservation Reserve Program (CRP) grasslands converted to bioenergy production. Proc Natl Acad Sci USA 2011;108:13864-9.

[32] Tilman D, Socolow R, Foley JA, Hill J, Larson E, Lynd L, et al. Beneficial biofuels - the food, energy, and environment trilemma. Science 2009;325:270-1.

[33] Johnston M, Licker R, Foley J, Holloway T, Mueller ND, Barford C, et al. Closing the gap: global potential for increasing biofuel production through agricultural intensification. Environ Res Lett 2011;6:034028. http:// dx.doi.org/10.1088/1748-9326/6/3/034028.

[34] Kinzig AP, Perrings C, Chapin III FS, Polasky S, Smith VK, Tilman D, et al. Paying for ecosystem services-promise and peril. Science 2011;334:603-4. 
[35] Koster RD, Dirmeyer PA, Guo Z, Bonan G, Chan E, Cox P, et al. Regions of strong coupling between soil moisture and precipitation. Science 2004;305:1138-40.

[36] Bonan GB, Lawrence PJ, Oleson KW, Levis S, Jung M, Reichstein $\mathrm{M}$, et al. Improving canopy processes in the Community Land Model version 4 (CLM4) using global flux fields empirically inferred from FLUXNET data. J Geophys Res 2011;116:G02014. http://dx.doi.org/10.1029/ 2010JG001593.

[37] LeBauer DS, Wang D, Richter KT, Davidson CC, Dietz MC. Facilitating feedbacks between field measurements and ecosystem models. Ecol Monogr 2013;83:133-54.

[38] Campbell GS, Norman JM. An introduction to environmental biophysics. 2nd ed. New York: Springer-Verlag; 1998.

[39] Hetherington AM, Woodward FI. The role of stomata in sensing and driving environmental change. Nature 2003;424:901-8.

[40] Berry JA, Beerling DJ, Franks PJ. Stomata: key player in the earth system, past, and present. Curr Opin Plant Biol 2010;13:233-40.

[41] Ball J, Woodrow I, Berry J. A model predicting stomatal conductance and its contribution to the control of photosynthesis under different environmental conditions. In: Biggins J, editor. Progress in Photosynthesis Research 7th Int. Congress. Dordrecht: Martinus Nijhoff; 1987. p. 221-4.

[42] Gedney N, Cox PM, Betts RA, Boucher O, Huntingford C, Stott PA. Detection of a direct carbon dioxide effect in continental river runoff records. Nature 2006;439:835-8.

[43] Huntington TG. Evidence for intensification of the global water cycle: review and synthesis. J Hydrol 2006;319:83-95.

[44] Huntington TG. $\mathrm{CO}_{2}$-induced suppression of transpiration cannot explain increasing runoff. Hydrol Process 2008;22:311-4.

[45] Bernacchi CJ, Kimball BA, Quarles DR, Long SP, Ort DR. Decreases in stomatal conductance of soybean under open-air elevation of $\left[\mathrm{CO}_{2}\right]$ are closely coupled with decreases in ecosystem evapotranspiration. Plant Physiol 2007;143:134-44.

[46] Mishra V, Cherkauer KA, Niyogi D, Lei M, Pijanowski BC, Ray DK. A regional scale assessment of land use/land cover and climatic changes on water and energy cycle in the upper Midwest United States. Int J Climatol 2010;30:2025-44.

[47] Song J. Phenological influences on the albedo of prairie grassland and crop fields. Int J Biometeor 1999;42(3):153-7.

[48] Twine TE, Bryant JJ, Richter KT, Bernacchi CJ, McConnaughay $\mathrm{KD}$, Morris SJ, et al. Impacts of elevated $\mathrm{CO}_{2}$ concentration on the productivity and surface energy budget of the soybean and maize agroecosystem in the Midwest USA. Glob Change Biol 2013. http://dx.doi.org/ 10.1111/gcb.12270.

[49] Dohleman FG, Long SP. More productive than maize in the Midwest: how does Miscanthus do it? Plant Physiol 2009;150(4):2104-15.

[50] Hickman GC, VanLoocke A, Dohleman FG, Bernacchi CJ. A comparison of canopy evapotranspiration for maize and two perennial grasses identified as potential bioenergy crops. GCB Bioenergy 2010;2:157-68.

[51] Findell KL, Eltahir EA. Atmospheric controls on soil moistureboundary layer interactions. Part II: feedbacks within the continental United States. J Hydrometeor 2003;4(3):570-83.

[52] Ek MB, Holtslag AAM. Influence of soil moisture on boundary layer cloud development. J Hydrometeor 2004;5:86-99.

[53] Arellano JV, van Heerwaarden CC, Lelieveld J. Modeled suppression of boundary-layer clouds by plants in a $\mathrm{CO}_{2}{ }^{-}$ rich atmosphere. Nat Geosci 2012;5(10):701-4.

[54] Anderson CJ, Anex RP, Arritt RW, Gelder BK, Khanal S, Herzmann DE, et al. Regional climate impacts of a biofuels policy projection. Geophys Res Lett 2013;40:1217-22.
[55] Bagley JE, Desai AR, Harding KJ, Snyder PK, Foley JA. Drought and Deforestation: has land cover change influenced recent precipitation extremes in the Amazon? J Clim 2014;27:345-61.

[56] Lobell DB, Bontils C. The effect of irrigation on regional temperatures: a spatial and temporal analysis of trends in California. J Clim 2008;21(10):2063-71.

[57] Sacks WJ, Cook BI, Buenning N, Levis S. Effects of global irrigation on the near surface climate. Clim Dyn 2009;33:159-75.

[58] Qian Y, Huang M, Yang B, Berg LK. A modeling study of irrigation effects on surface fluxes and land-air-cloud interactions in the Southern Great Plains. J Hydrometeor 2013;14:700-21.

[59] Wang J, Chagnon FJF, Williams ER, Betts AK, Renno NO, Machado LAT, et al. Impact of deforestation in the Amazon basin on cloud climatology. Proc Natl Acad Sci USA 2009;106:3670-4.

[60] Katul GG, Oren R, Manzoni S, Higgins C, Parlange MB. Evapotranspiration: a process driving mass transport and energy exchange in the soil-plant-atmosphere-climate system. Rev Geophys 2012;50:RG3002. http://dx.doi.org/ 10.1029/2011RG000366.

[61] Roy SB. Mesoscale vegetation-atmosphere feedbacks in Amazonia. J Geophys Res 2009;114:D20111. http:// dx.doi.org/10.1029/2009JD012001.

[62] Georgescu M, Weaver CP, Avissar R, Walko RL, Gonzalo MM. Sensitivity of model-simulated summertime precipitation over the Mississippi River Basin to the spatial distribution of initial soil moisture. J Geophys Res 2003;108:8855. http:// dx.doi.org/10.1029/2002JD003107.

[63] Bagley JE, Desai AR, Dirmeyer PA, Foley JA. Effects of land cover change on moisture availability and potential crop yield in the world's breadbaskets. Environ Res Lett 2012;7:014009. http:// dx.doi.org/10.1088/1748-9326/7/1/014009.

[64] Harding KJ, Snyder PK. Modeling the atmospheric response to irrigation in the Great Plains. Part I: general impacts on precipitation and the energy budget. J Hydrometeor 2012;13:1667-86.

[65] Pan Z, Takle E, Segal M, Turner R. Influences of model parameterization schemes on the response of rainfall to soil moisture in the central United States. Mon Weather Rev 1996;124:1786-802.

[66] Pal PS, Eltahir EAB. Pathways relating soil moisture conditions to future summer rainfall within a model of the land-atmosphere system. J Clim 2001;14:1227-42.

[67] Giorgi F, Mearns LO, Shields C, Mayer L. A regional model study of the importance of local versus remote controls of the 1988 drought and 1993 flood over the central United States. J Clim 1996;9:1150-62.

[68] Pitman AJ, Avila FB, Abramowitz G, Wang YP, Phipps SJ, de Noble-Ducoudre N. Importance of background climate in determining impact of land-cover change on regional climate. Nat Clim Change 2011;1:472-5.

[69] Snyder P, Delire C, Foley J. Evaluating the influence of different vegetation biomes on the global climate. Clim Dyn 2004;23:279-302.

[70] Swann ALS, Fung I, Chiang JCH. Mid-latitude afforestation shifts general circulation and tropical precipitation. Proc Natl Acad Sci USA 2012;109:712-6.

[71] Fargione J, Hill J, Tilman D, Polasky S, Hawthorne P. Land clearing and the biofuel carbon debt. Science 2008;319:1235-8.

[72] Gibbs HK, Johnston M, Foley JA, Holoway T, Monfreda C, Ramankutty N, et al. Carbon payback times for crop-based biofuel expansion in the tropics: the effects of changing yield and technology. Environ Res Lett 2008;3:034001. http:// dx.doi.org/10.1088/1748-9326/3/3/034001. 
[73] Zeri M, Anderson-Teixeira KJ, Hickman G, Masters M, DeLucia EH, Bernacchi CJ. Carbon exchange by establishing biofuel crops in Central Illinois. Agric Ecosyst Environ 2011;144:319-29.

[74] Anderson-Teixeira KJ, Snyder PK, Twine TE, Cuadra SV, Costa MH, Delucia EH. Climate-regulation services of natural and agricultural ecoregions of the Americas. Nat Clim Change 2012;2:177-81.

[75] Zenone T, Gelfand I, Chen J, Hamilton SK, Robertson GP. From set-aside grassland to annual and perennial cellulosic biofuel crops: effects of land use change on carbon balance. Agric For Meteor 2013;182-138:1-12.

[76] Charney J, Stone PH, Quirk WJ. Drought in the Sahara: a biogeophysical feedback mechanism. Science 1975;187:434-5.

[77] Pitman AJ. The evolution of, and revolution in, land surface schemes designed for climate models. Int J Climatol 2003;23:479-510.

[78] Gutman G, Ignatov A. The derivation of green vegetation fraction from NOAA/AVHRR data for use in numerical weather prediction models. Int J Remote Sens 1998;19:1533-43.

[79] Weaver CP, Avissar R. Atmospheric disturbances caused by human modification of the landscape. Bull Am Meteor Soc 2001;82:269-81.

[80] Georgescu M, Lobell DB, Field CB. Potential impact of U.S. biofuels on regional climate. Geophys Res Lett 2009;36:L21806. http://dx.doi.org/10.1029/2009GL040477.

[81] Pitman AJ, De Noblet-Ducoudre N, Cruz FT, Davin EL, Bonan GB, Brovkin V, et al. Uncertainties in climate responses to past land cover change: first results from the LUCID intercomparison study. Geophys Res Lett 2009;36. http://dx.doi.org/10.1029/2009GL039076.

[82] De Noblet-Ducoudre N, Boisier JP, Pitman A, Bonan GB, Brovken V, Cruz F, et al. Determining robust impacts of land-use-induced land cover changes on surface climate over North America and Eurasia: results from the first set of LUCID Experiments. J Clim 2012;25:3261-81.

[83] Bernacchi CJ, Leakey ADB, Kimball BA, Ort DR. Growth of soybean at future tropospheric ozone concentrations decreases canopy evapotranspiration and soil water depletion. Environ Pollut 2011;159:1464-72.

[84] Hussain MZ, VanLoocke A, Siebers MH, Ruiz-Vera UM, Markelz CRJ, Leakey ADB, et al. Future carbon dioxide concentration decreases canopy evapotranspiration and soil water depletion by field grown maize. Glob Change Biol 2013;5:1572-84.

[85] Le PVV, Kumar P, Drewry DT. Implications for the hydrologic cycle under climate change due to the expansion of bioenergy crops in the Midwestern United States. Proc Natl Acad Sci USA 2011;108(37):15085-90.

[86] Ruiz-Vera UM, Siebers M, Gray SB, Drag DW, Rosenthal DM, Kimball BA, et al. Global warming can negate the expected $\mathrm{CO}_{2}$ stimulation in photosynthesis and productivity for soybean grown in the Midwest United States. Plant Physiol 2013;162(1):410-23.

[87] Ainsworth EA, Long SP. What have we learned from 15 years of free air $\mathrm{CO}_{2}$ enrichment (FACE)? A meta-analytic review of the responses of photosynthesis, canopy properties and plant production to rising CO2. New Phytol 2005;165:351-72.

[88] Bhardwaj AK, Zenone T, Jasrotia P, Robertson GP, Chen J, Hamilton SK. Water and energy footprints of bioenergy crop production on marginal lands. GCB Bioenergy 2011;3:208-22.

[89] Suyker AE, Verma SB. Evapotranspiration of irrigated and rainfed maize-soybean cropping systems. Agric For Meteor 2009;149:443-52.

[90] Bernacchi CJ, Bagley JE, Serbin SP, Ruiz-Vera UM, Rosenthal DV, VanLoocke A. Modelling $C_{3}$ photosynthesis from the choloroplast to the ecosystem. Plant Cell Environ 2013;36:1641-57.

[91] Abramowitz G, Gupta H. Toward a model space and model independence metric. Geophys Res Lett 2008;35. http:// dx.doi.org/10.1029/2007/GL032834.

[92] Dietze MC, LeBauer D, Kooper R. On improving the communication between models and data. Plant Cell Environ 2013;36:1575-85.

[93] Kurkowski NP, Strensrud DJ, Baldwin ME. Assessment of implementing satellite-derived land cover data in the Eta Model. Weather Forecast 2003;18:404-16.

[94] Skamarock WC, Klemp JB, Dudhia J, Gill DO, Barker DM, Duda MG, et al. A description of the advanced research WRF version 3. 2008. p. 125. NCAR Technical Note, NCAR/TN$475+$ STR.

[95] Lyon SW, Dominguez F, Gochis DJ, Brunsell NA, Castro C, Chow FK, et al. Coupling terrestrial and atmospheric water dynamics to improve prediction in a changing environment. Bull Am Meteor Soc 2008;89:1275-9.

[96] Choi HI, Liang XZ. Improved terrestrial hydrologic representation in mesoscale land surface models. J Hydrometeor 2010;11(3):797-809.

[97] Fan Y, Miguez-Macho G. A simple hydrologic framework for simulating wetlands in climate and earth system models. Clim Dyn 2011;37(1-2):253-78.

[98] VanLoocke A, Twine TE, Zeri M, Bernacchi CJ. A regional comparison of water use efficiency for miscanthus, switchgrass and maize. Agric For Meteor 2011;164:82-95.

[99] Drewry DT, Kumar P, Long S, Bernacchi C, Liang X-Z, Sivapalan M. Ecohydrological responses of dense canopies to environmental variability: 1. Interplay between vertical structure and photosynthetic pathway. J. Geophys. Res. 2010;11. http://dx.doi.org/10.1029/2010JG001340.

[100] Pielke RA, Dalu G, Snook J, Lee T, Kittel T. Nonlinear influence of mesoscale land use on weather and climate. J Clim 1991;4(11):1053-69.

[101] Fan Y, Miguez-Macho G, Weaver CP, Walko R, Robock A. Incorporating water table dynamics in climate modeling: 1. Water table observations and equilibrium water table simulations. J Geophys Res 2007;112:D10125. http:// dx.doi.org/10.1029/2006JD008111.

[102] Avissar R, Liu Y. Three-dimensional numerical study of shallow convective clouds and precipitation induced by land surface forcing. J Geophys Res 1996;101(D3): 7499-518.

[103] Rodell M, Houser PR, Jambor U, Gottschalck J, Mitchell K, Meng CJ, et al. The global land data assimilation system. Bull Am Meteor Soc 2004;85:381-94.

[104] Zaitchik BF, Rodell M, Olivera F. Evaluation of the global land data assimilation system using global river discharge data and a source-to-sink routing scheme. Water Resour Res 2010;46:W06507. http://dx.doi.org/10.1029/2009WR007811.

[105] BP statistical review of world energy. 2013 (Available from: https://www.bp.com/statisticalreview.

[106] Brazil Ministry of Agriculture. Statistical yearbook of agrienergy 2012. 2013 (Available from: http://www.agricultura. gov.br/arq_editor/file/Desenvolvimento_Sustentavel/ Agroenergia/anuario_agroenergia_web_2012.pdf.

[107] USDA statistics. Economic Research Service (ERS); (Available from: http://www.usda.gov/wps/portal/usda/ usdahome? navid=DATA_STATISTICS).

[108] Monfreda C, Ramankutty N, Foley JA. Farming the planet: 2. Geographic distribution of crop areas, yields, physiological types, and net primary production in the year 2000. Glob Biogeochem Cycles 2008;22:GB1022. http://dx.doi.org/ 10.1029/2007GB002947.

[109] Bagley JE, Desai AR, West PC, Foley JA. A simple, minimal parameter model for predicting the influence of changing 
land cover on the land-atmosphere system. Earth Interact 2011;15:1-32.

[110] New M, Lister D, Hulme M, Makin I. A high-resolution data set of surface climate over global land areas. Clim Res 2002;21:1-25.

[111] U.S. DOE. Breaking the biological barriers to cellulosic ethanol: a joint research agenda. U.S. Department of Energy
Office of Science and Office of Energy Efficiency and Renewable Energy; 2006. DOE/SC-0095. Available from: www.doegenomestolife.org/biofuels/.

[112] Berndes G. Bioenergy and water - the implications of largescale bioenergy production for water use and supply. Glob Environ Change 2002;12:253-71. 